OPEN ACCESS

Edited by:

Shiyong Yu,

Jiangsu Normal University, China

Reviewed by:

Hao Long,

Nanjing Institute of Geography and Limnology (CAS), China

Zhiwei Xu,

Nanjing University, China

*Correspondence:

Mingrui Qiang

mrqiang@scnu.edu.cn

Specialty section:

This article was submitted to

Quaternary Science, Geomorphology and Paleoenvironment, a section of the journal

Frontiers in Earth Science

Received: 31 January 2021

Accepted: 25 March 2021

Published: 14 April 2021

Citation:

Qiang M, Stevens T, Li G, Hu L, Wang X, Lang W and Chen J (2021)

Late Quaternary Dust, Loess and Desert Dynamics in Upwind Areas of the Chinese Loess Plateau.

Front. Earth Sci. 9:661874.

doi: 10.3389/feart.2021.661874

\section{Late Quaternary Dust, Loess and Desert Dynamics in Upwind Areas of the Chinese Loess Plateau}

\author{
Mingrui Qiang ${ }^{1,2 *}$, Thomas Stevens ${ }^{3}$, Guoqiang $\mathrm{Li}^{2}$, Ling $\mathrm{Hu}^{2}$, Xiaowei Wang ${ }^{2}$, \\ Wenzhe Lang ${ }^{2}$ and Jie Chen ${ }^{1}$
}

${ }^{1}$ School of Geography, South China Normal University, Guangzhou, China, ${ }^{2}$ MOE Key Laboratory of Western China's Environmental Systems, Lanzhou University, Lanzhou, China, ${ }^{3}$ Department of Earth Sciences, Uppsala University, Uppsala, Sweden

As a key global climate and dust archive, the nature of Chinese loess generation, transport and deposition remains debated. The lack of consensus on dust dynamics from sources to leeward regions fundamentally limits interpretation of the preserved past climate and dust record. Here, we investigate chronostratigraphic variability of aeolian deposits in upwind regions of the modern Chinese Loess Plateau (CLP) and attempt to understand dust dynamics that potentially affects loess deposition downwind. The strata consist of alternating layers of typical loess, well-sorted sand, and sandy loess, with obvious unconformities occurring at the transitions from loess to sand. We suggest that pre-existing typical loess in regions to the northwest of the modern CLP was eroded by wind, providing a significant source of homogeneous dust for the dust deposits downwind. The sand deposits interbedded with typical loess at the study sites suggests that proximal deserts have greatly expanded and contracted repeatedly prior to the Holocene. However, the spatial extents of the deserts, as inferred from the sections here, have not markedly diminished after the major expansion during the Last Glacial Maximum. Such a pattern of proximal desert dynamics plays an important role in regulating dust emission and transport, strongly affecting dust sequences on the CLP. Our results suggest a complex scenario of dust dynamics in upwind regions of the CLP at least over the Late Quaternary; the involved processes have to be considered when using conventional proxies from Chinese loess deposits to recover the history of climate and dust changes.

Keywords: dust, aeolian deposits, erosional hiatus, proximal desert, Chinese loess

\section{INTRODUCTION}

As one of the world's key climate archives, Chinese loess deposits have been widely used to decipher changes in continental environments and atmospheric circulation on various timescales (e.g., Hovan et al., 1989; Liu and Ding, 1998; Guo et al., 2002; Sun et al., 2012; Licht et al., 2014). However, the nature of loess generation and deposition and the processes that could affect these have generally not been investigated in detail within loess-based climatic reconstructions, with most studies assuming largely consistent dust emission, transport and deposition for given intervals. 
Chinese loess deposits are mainly derived from the arid and semiarid regions of China, constituting source proximal dust deposits of the Asian aeolian system (Rea, 1994; Biscaye et al., 1997; Uno et al., 2009; Shao et al., 2011). Thus, loess deposition must be affected by a complex range of surface processes and local influences (Stevens et al., 2006), including aridity in source areas, dust transport capacity, and changes in the scope of source areas and hence in materials supplying dust. Kapp et al. (2015) mapped the landforms of the Ordos Basin and the northern Chinese Loess Plateau (CLP), and concluded that thick loess may have been previously distributed in areas further to the north and west than the present CLP, but was subsequently eroded by winds, supplying homogeneous dust to younger loess deposits leeward. This work emphasized that loess in upwind regions from the current CLP would be a previously unrecognized dust source, suggesting a process of "aeolian cannibalism" of previously deposited loess. A large amount of zircon U-Pb data from loess and different potential dust source deposits suggest that a substantial portion of interglacial dust is recycled from older glacial loess (Licht et al., 2016), implying reworking of older loess deposits by wind. Furthermore, multiple erosional hiatuses during the past $300 \mathrm{ka}$, recorded by loess deposits at Jingbian, provide independent evidence that supports the hypothesis of loess cannibalization from CLP marginal areas (Stevens et al., 2018). These findings therefore call for urgent reassessments of changes in potential sources of Chinese loess, of accepted interpretations of climatic proxies applied to loess deposits, such as sedimentation rate and grain size, of Quaternary dust dynamics in this globally important dust emission region, and even exactly how the Chinese loess time series can represent large-scale climatic changes. To test these findings requires analysis of the complex sedimentary system source to sink, including understudied aeolian sediment that lies between the main CLP and the main source areas. However, to date, beyond a few well dated sites ( $\mathrm{Xu}$ et al., 2018), there is still a lack of chronostratigraphic evidence over the age and geographical extent of loess upwind of the main CLP. Potential previously active depositional regions are currently dominated by desert landscapes and subjected to intense aeolian erosion. This means the potential for pre-existing loess to act as a dust source and for the influence of proximal desert activity on loess accumulation on the CLP remains unclear.

In this study, we investigate chronostratigraphic variability and changes in grain size of aeolian deposits outside the boundary of the modern CLP, focusing on dust activity in upwind areas of the CLP and its potential impacts on loess accumulation downwind. Here, the "upwind areas" is referred to by considering the modern transition zone between proximal deserts and the loess plateau and the areas today characterized by patches of moving sand. This work aims to understand (1) the possible distribution of pre-existing loess areas in upwind regions of the CLP, (2) the influence of dust entrained from pre-existing loess on the CLP loess, and (3) the evolution of proximal deserts during the Late Quaternary and the potential impact on loess sequences. Our results provide insights into dust dynamics in regions upwind of the CLP, which are crucial for understanding environmental and climatic changes recorded by loess sequences from the CLP and in constraining the specific dust source areas of one of the most important dust source regions in the world.

\section{STUDY SITES AND METHODS}

As an intermediate product of airborne transport, aeolian deposits between proximal deserts and the CLP share features of both source materials and loess deposits (Qiang et al., 2010), and thus are a crucial link in deciphering dust dynamics between source areas to dust depositional regions. Three outcrop sections of aeolian deposits at two sites northwest of the modern CLP were selected for detailed investigation (Figures 1, 2). Two sections in the Xiangshan Mountains (sections XS-A and XS-B; $37^{\circ} 20^{\prime} 8^{\prime \prime} \mathrm{N}$, $105^{\circ} 13^{\prime} 36^{\prime \prime} \mathrm{E}$ ) are on a rocky platform of tectonic origin along the central northern slopes of the range, which is separated from the Tengger Desert by the Yellow River (Figures 1, 2). The site is at an altitude of $1645 \mathrm{~m}$ a.s.l. and is $\sim 500 \mathrm{~m}$ higher than the Yellow River. The mean annual temperature and precipitation of the area were $9.7^{\circ} \mathrm{C}$ and $187 \mathrm{~mm}$, respectively during 1965-1980 (Qiang et al., 2010), and the maximum wind speed in spring was $29.1 \mathrm{~m} \mathrm{~s}^{-1}$. The Kajia section (KJ; $35^{\circ} 33^{\prime} 27.6^{\prime \prime} \mathrm{N}, 100^{\circ} 58^{\prime} 44.3^{\prime \prime} \mathrm{E}$ ) is located at the southeastern margin of the Mugetan Sandy Land in the Gonghe Basin on the NE edge of the Qinghai-Tibetan plateau, at an altitude of $3280 \mathrm{~m}$ a.s.l. (Figures 1, 2). The mean annual temperature and rainfall were $2.3^{\circ} \mathrm{C}$ and $403 \mathrm{~mm}$ over the past 50 years.

Bulk samples were collected from the sections at intervals of 2$10 \mathrm{~cm}$. Sediment grain-size distributions were measured using a laser particle analyzer (Malvern Mastersizer 2000), after removing organic matter and carbonate by $\mathrm{H}_{2} \mathrm{O}_{2}$ and $\mathrm{HCl}$ followed by dispersion with $\left(\mathrm{NaPO}_{3}\right)_{6}$. The measurement range is $0.02-$ $2000 \mu \mathrm{m}$.

Considering that the quartz optically stimulated luminescence (OSL) signal is likely to be saturated for pre-Late Quaternary strata, the chronologies of sections XS-B and KJ and the age of sample XS-A-07 are determined using K-feldspar post-IR InfraRed Stimulated Luminescence (IRSL) techniques (Buylaert et al., 2012, 2015). Sample preparation followed the methods described by Aitken (1998). All laboratory processing, including sample preparation and luminescence measurements, was carried out in a darkroom under subdued red light in the Luminescence Laboratory at Lanzhou University, China. All samples were treated with $10 \% \mathrm{HCl}$ and $20 \% \mathrm{H}_{2} \mathrm{O}_{2}$ to remove carbonate and organic matter, respectively, and then wet sieved to extract sediments of grain sizes of 63/90-125 $\mu \mathrm{m}$. Heavy liquid with a density of $2.58 \mathrm{~g} \mathrm{~cm}^{-3}$ was used to separate the K-feldspar fraction of each sample. The K-feldspar grains were treated with $10 \% \mathrm{HF}$ for $40 \mathrm{~min}$ to remove the outer layer irradiated by alpha particles. All samples were further treated with $1 \mathrm{~mol} \mathrm{l}^{-1} \mathrm{HCl}$ for $10 \mathrm{~min}$ to remove fluorides produced during the HF etching. K-feldspar IRSL signal was measured using an automated Risø TL/OSL-DA-20 reader. Laboratory irradiation was carried out using ${ }^{90} \mathrm{Sr} /{ }^{90} \mathrm{Y}$ sources mounted within the reader. The IRSL signal was detected using a photomultiplier tube with the IRSL passing through BG-39 and Coring-759 filters. A pIRIR dating protocol, utilizing a post-IR IRSL signal stimulated at $290^{\circ} \mathrm{C}$, 

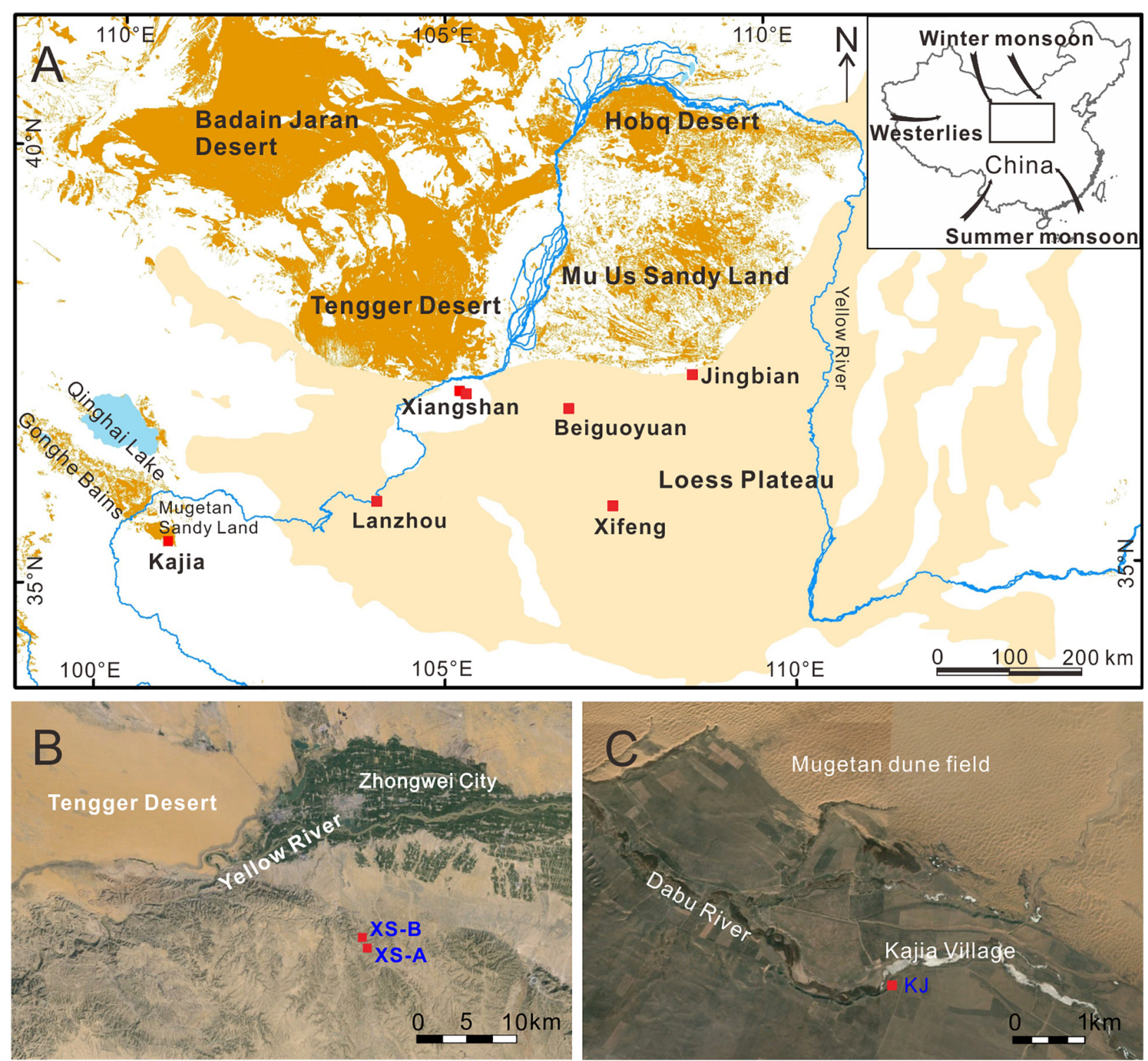

FIGURE 1 | Physical environments along the boundary between proximal deserts and the Chinese Loess Plateau (A). Locations of the studied sites and the referenced loess sites are shown by red solid squares. Close-up view (Google Earth ${ }^{T M}$ ) of the physical environments surrounding sections XS-A/B (B) and KJ (C)

was used for K-feldspar equivalent dose determination of coarsegrained K-feldspar (60/90-125 $\mu \mathrm{m})$.

A prior IR stimulation temperature plateau test (Buylaert et al., 2012; Yi et al., 2016, 2018) was conducted on the sand sample XS-A-07 to check the stability of the pIRIR signal. The pIRIR $D_{e}$ values were obtained in six groups of aliquots with different prior IR stimulation temperature from 50 to $270^{\circ} \mathrm{C}$ measured at $30^{\circ} \mathrm{C}$ intervals (three aliquots each group). The pIRIR $\mathrm{D}_{\mathrm{e}} \mathrm{s}$ have not shown an obvious trend with prior IR stimulation temperature increasing from 50 to $230^{\circ} \mathrm{C}$ (Figure 3), indicating the stability of pIRIR signal. A prior IR stimulation temperature of $50^{\circ} \mathrm{C}$ is used in pIRIR dating protocol.

A dose recovery test was conducted on sunlight bleached samples XS-B-01 (sand) and XS-A-07 (loess) to check the suitability of the chosen pIRIR dating protocol. Seven aliquots of each sample were bleached under sunlight for $28 \mathrm{~h}$ in March in Lanzhou, China. The residual dose of each sample was measured by using the pIRIR dating protocol and then a given dose of the 59.4 Gy was added to four bleached aliquots of sample XS-B-01 and a given dose of 297 Gy were added to four bleached aliquots of sample XS-A-07. The pIRIR $D_{e}$ of these two samples are then measured by using the pIRIR dating protocol. The measured/given dose ratio of the K-feldspar sample XS-B-01 and XS-A-07 is $0.91 \pm 0.01$ and $0.89 \pm 0.02$, respectively. If the measured residual doses of $4.63 \pm 0.13 \mathrm{~Gy}$ and $7.85 \pm 0.40$ Gy were subtracted from the corresponding measured dose, the measured/given dose ratios are $0.83 \pm 0.01$ and $0.86 \pm 0.02$. Given the 

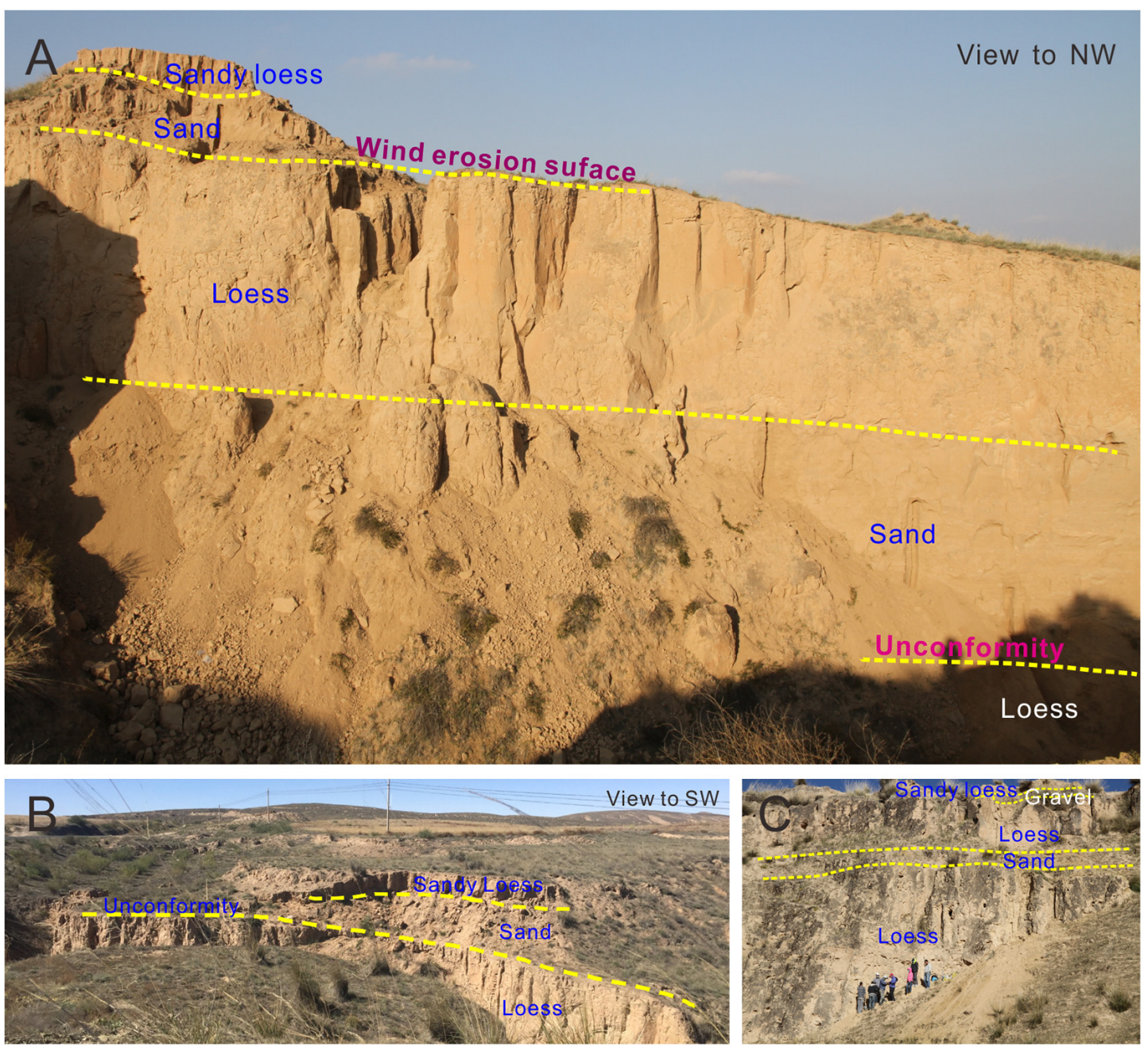

FIGURE 2 | Photographs of sections XS-B (A), XS-A (B), and KJ (C). Dashed lines indicate stratigraphic boundaries. Flat surfaces, clearly identified at the transitions from loess to sand deposition in the section, are characterized by abrupt alternation of sediment, no signs of fluvial activity, and inclination to the direction of prevalent winds in winter and spring seasons, indicating erosional hiatuses by wind.

uncertainty of the measurement of the residual dose, these measured/given dose ratios are considered acceptable for the pIRIR dating protocol.

The environmental dose rate was calculated from the measurements of radioactive element concentrations in the sample with a small contribution from cosmic rays. For all samples, the concentrations of uranium (U), thorium (Th), and potassium $(\mathrm{K})$ were determined using neutron activation analysis (NAA). All results were converted to beta and gamma dose rates using the conversion factors by Guérin et al. (2011). The dose rate from cosmic rays was calculated from the sample burial depth and the altitude of the section (Prescott and Hutton, 1994). The internal dose rate of $\mathrm{K}$-feldspar grains was calculated with a $\mathrm{K}$ content of $12.5 \% \pm 0.5 \%$ (Huntley and Baril, 1997) and a Rb content of $400 \pm 100$ ppm (Huntley and Hancock, 2001). The measured in situ water content was used to calculate ages for all loess/sand samples. Fifty percent of individual measured value was taken as water content errors.

\section{RESULTS}

\section{Stratigraphic Variability}

The stratigraphic units of the aeolian deposits are easily identified in the field and are mainly composed of loess, aeolian sand, and sandy loess/paleosol in the upper parts of the sequences (Figure 4A). Aeolian sand is homogenous and yellowish in color, with a loose structure. Loess is homogenous, finer and denser compared to the aeolian sand, and has no visible signs of pedogenic alteration. Sandy loess contains several weakly developed paleosols characterized by a massive and dense structure, abundant apertures, and secondary filamentous carbonates. These features make the paleosols more resistant to wind erosion compared to sand layers, resulting in the formation of loess/paleosol cliffs due to sand collapse (Figure 2B). In section $\mathrm{KJ}$, aeolian deposition was interrupted by fluvial processes at a depth of $250 \mathrm{~cm}$, producing a layer of gravels and overbank silty sand deposits (Figures 2C, 4A). 


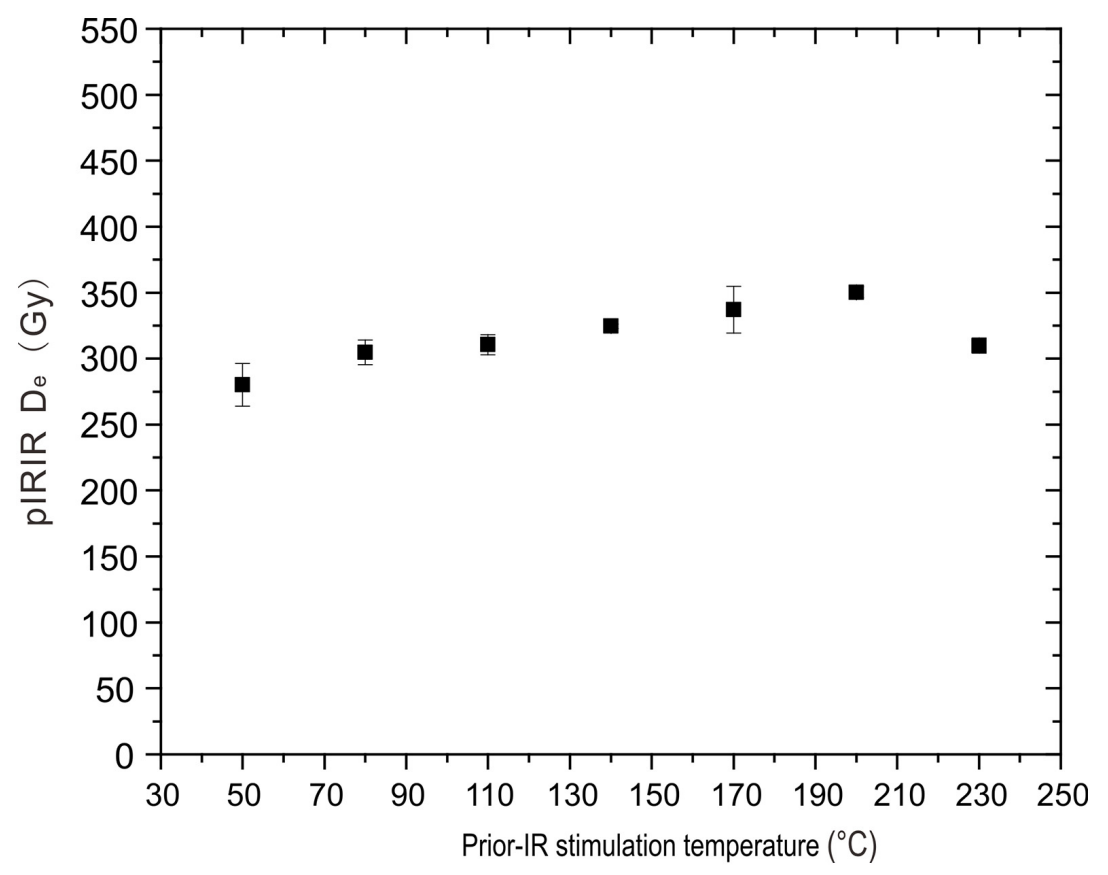

FIGURE 3 | Plot of pIRIR De to prior IR stimulation temperature for K-feldspar sample XS-A-07.

\section{Luminescence Dating}

Together with previously published quartz OSL ages (Qiang et al., 2010) and a quartz OSL age from section XS-A (sample XS-A-04) using the same methodology, 21 luminescence dates are presented here (Figure 4A and Table 1). The decay curves and growth curves for coarse-grained K-feldspar sample XSB-02 are shown in Figure 5. The initial pIRIR 290 signal shows much higher values compared to the $I_{50}$ signal. The growth curve for the sample can be readily fitted using a single saturation exponential function. The $2 \mathrm{D}_{0}$ (luminescence saturation parameter) estimated from the growth curves of pIRIR $_{290}$ signal of the sample is $694 \pm 37 \mathrm{~Gy}$, indicating an upper limit of $700 \mathrm{~Gy}$ of pIRIR 290 signal for samples from this region. Similarly, the pIRIR 290 signal has shown a similar but slightly higher saturation dose of $800 \mathrm{~Gy}$ for loess samples from the Jingbian desert marginal site (Stevens et al., 2018). As a result of saturated or near saturated signals $\left(\mathrm{D}_{\mathrm{e}}\right.$ value exceeding c. $700 \mathrm{~Gy}$, the average $2 \mathrm{D}_{0}$ value for these samples), the K-feldspar pIRIR ages from the lower parts of sections XS-B and KJ are taken as minimum age estimates (Table 1). Although we attempted to constrain the chronology of sub-strata in the lower parts of the sections, the results suggest that these deposits seem to be much older than the upper age limit of applied luminescence dating strategy. Nonetheless, the obvious changes in the nature of the deposits, as described previously, are still useful in investigating alternations of dust dynamics in the past.

\section{Grain Size}

The loess is dominated by silt-sized material, with modal sizes varying from 30 to $50 \mu \mathrm{m}$ (Figure 6). In contrast, the aeolian sand has a modal size of $>100 \mu \mathrm{m}$ and contains a small amount of fine silt $(<20 \mu \mathrm{m})$. Within sections XS-A and XS-B, the mean grain sizes $\left(M_{z}\right)$ of the loess and aeolian sand fluctuate around 45 and $100 \mu \mathrm{m}$, respectively (Figure $\mathbf{4 A}$ ). The $M_{z}$ of the sand deposits in section KJ is slightly coarser than in sections XS-A and XS-B. This may be because the elevation of the site is similar to that of the upwind dune fields, which are relatively close to the section (Figure 1C). The $M_{z}$ of sandy loess in the upper sections at these sites varies between values typical of aeolian sand and loess in the sections, reflecting mixtures of sand-sized particles and loess silts. In section XS-A, the $>63 \mu \mathrm{m}$ fraction exhibits a changing pattern very similar to that of the $M_{z}$. The sand fraction in loess accounts for around $30 \%$, while in aeolian sand, approximating to $90 \%$. Moderate percentages of the sand fraction $(40-50 \%)$ are observed in sandy loess (Figure 4A).

\section{DISCUSSION}

\section{Potential Reworking of Pre-existing Loess in Upwind Areas}

The strongly contrasting strata suggest that the deposition at the study sites was episodically dominated by distinctly different aeolian dynamics and depositional settings. The loess deposits have grain-size distributions very similar to that of a typical loess sample from Lanzhou in the western CLP (Figure 6). Given windward nature of the loci where aeolian deposits are preserved, the loess strata likely represent intervals dominated by a steppe environment, which can effectively protect deposited loess from subsequent aeolian erosion (Sun and Ding, 1998). By contrast, the aeolian sand is well-sorted, with grain-size 


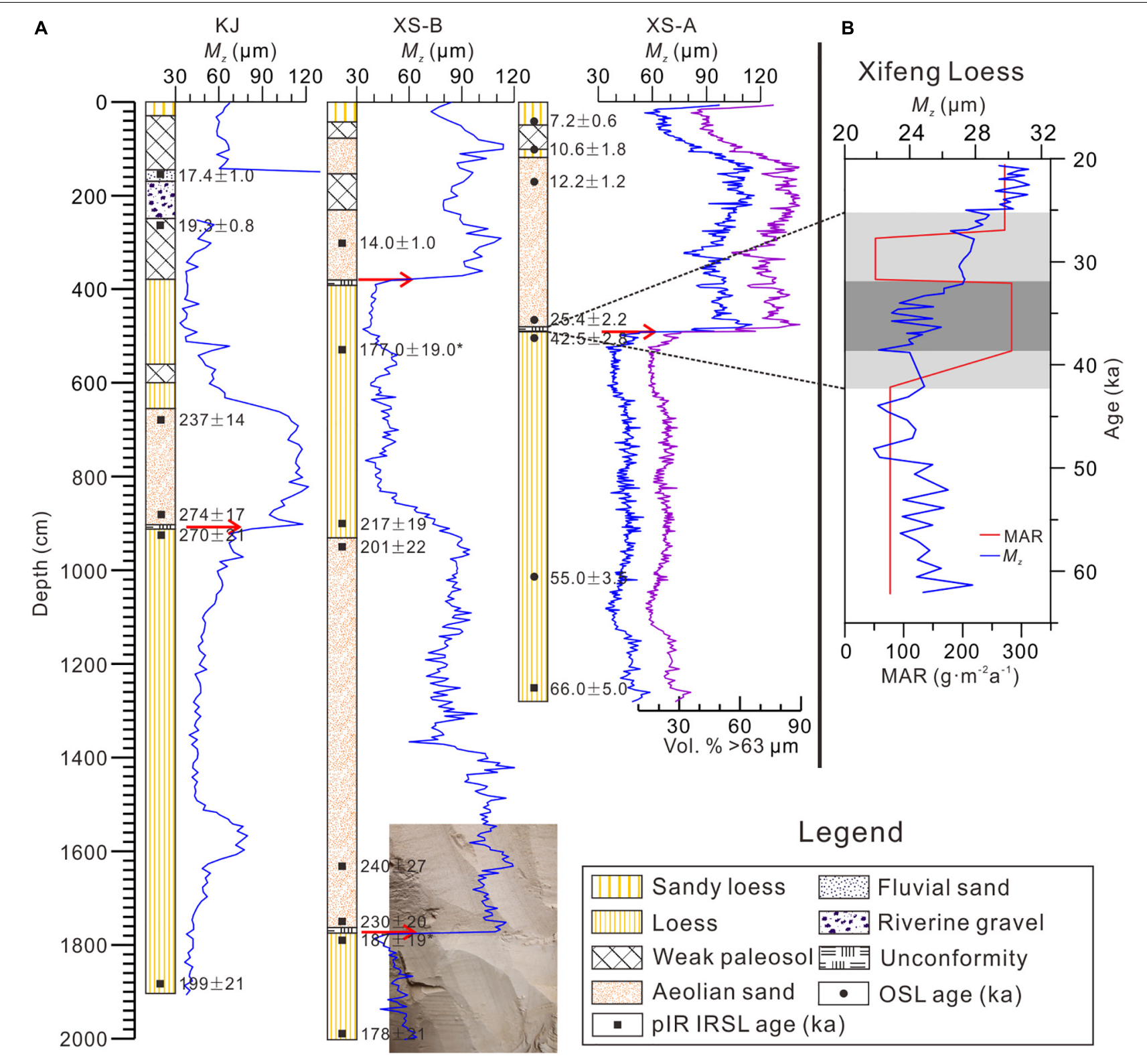

FIGURE 4 | Stratigraphy and variations in mean grain-size $\left(M_{z}\right)$ of aeolian deposits in sections XS-A, XS-B, and KJ (A). For section XS-A, changes in the sand fraction $(>63 \mu \mathrm{m})$ are shown by a purple line. Red arrows indicate abrupt changes in $M_{z}$, representing unconformities. Photograph shows an unconformity between loess and aeolian sand. Changes in mass accumulation rate (MAR) and $M_{z}$ of the Xifeng loess during the last glacial (Stevens et al., 2016) (B), which are compared with an unconformity occurring between 42.5 and 25.4 ka in section XS-A. The inconsistency between MAR and $M_{z}$ from 39 to 32 ka is highlighted in darker gray.

distributions similar to that of a sand sample from mobile dunes, although the grain sizes are finer overall than the latter (Figure 6). At the XS site, sand deposition has been ascribed to the piling-up of sand due to the frequent occurrence of sandladen storms across the adjacent deserts and to topographical effects, since in situ desertification and development of climbing dunes were ruled out (Qiang et al., 2010). Thus, compared to the interbedded loess, the sand deposits reflect either a reduced distance from sand sources to the sites and/or a strong wind regime (e.g., Ding et al., 1999); however, if so, this does not exclude the possibility that dune fields may have expanded into the vicinity of section KJ, given their similar altitude.

Abrupt increases in $M_{z}$ occurred at the transitions from loess to aeolian sand, i.e., roughly varying from 45 to $100 \mu \mathrm{m}$ (Figure 4A); whereas from aeolian sand to loess layers, the $M_{z}$ decreases in a gradual manner. The abrupt grain-size changes are also clearly reflected in the distinctly different degree of compactness of loess and sand, as observed in the field. These points to sedimentation discontinuities at the loess to sand transitions. There are no signs of fluvial sediments and/or fluvial disturbance in the vicinity of the unconformities. Furthermore, 


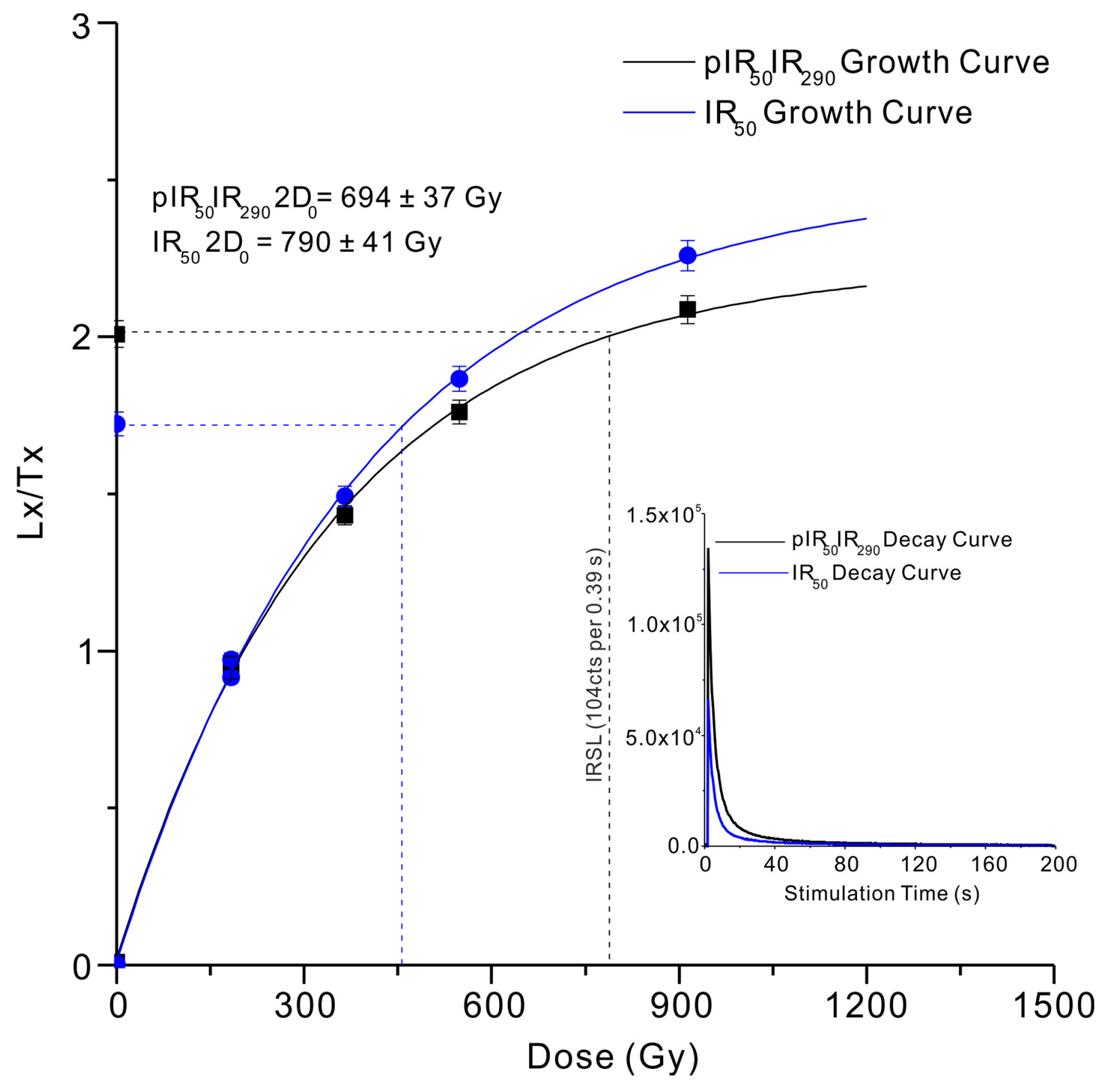

FIGURE 5 | Decay curves and growth curves of K-feldspar sample XS-B-02.

the unconformity surfaces are easily identified in a large exposed area around the sampled sections (Figure 2), and are almost flat, slightly inclined to northwest (Figures 2A,B). The inclination is largely consistent with the direction of prevalent winds in seasons of intense aeolian activity in the study areas (Sun et al., 2001; Qiang et al., 2014). Thus, we argue that the abrupt changes in grain size and alteration of stratigraphic units could represent unconformities induced by aeolian erosion. There are at least four such stratigraphically identified hiatuses in the studied sections (Figure 4A). An apparent hiatus occurred from 42.5 to $25.4 \mathrm{ka}$ in section XS-A, probably corresponding to one appearing at the depth of $390 \mathrm{~cm}$ in section XS-B, in light of an age of $14 \mathrm{ka}$ from the middle of overlying sand layer. During this 17-ka interval, airborne material may not have settled, and/or previously deposited loess may have been partially eroded by wind. We consider that the latter is very likely, taking into account the geomorphological signs and the drastic changes in grain size at the study sites described above. The exact timings of hiatuses in the lower parts of sections XS-B and KJ cannot be constrained due to the saturated luminescence signals meaning only minimum ages can be provided, and the large uncertainties inherent in the obtained dates.

Accounting for the locations of aeolian deposits, their stratigraphic variability and the OSL/pIR IRSL dating, our results show that typical loess was previously deposited in the regions northwest to the CLP. The multiple erosional hiatuses 
TABLE 1 | Luminescence dating results.

\begin{tabular}{|c|c|c|c|c|c|c|c|c|c|c|c|c|c|}
\hline Section & $\begin{array}{l}\text { Sample } \\
\text { No. }\end{array}$ & $\begin{array}{l}\text { Sediment } \\
\text { type }\end{array}$ & $\begin{array}{l}\text { Depth } \\
\text { (cm) }\end{array}$ & Mineral & $\begin{array}{l}\text { Grain size } \\
\qquad(\mu \mathrm{m})\end{array}$ & $\begin{array}{c}\text { Water content } \\
(\%)^{\mathrm{b}}\end{array}$ & U (ppm) & Th (ppm) & K (\%) & $\begin{array}{l}\text { Dose rate } \\
\text { (Gy/ka) }\end{array}$ & $D_{e}(G y)$ & Age (ka) & Reference \\
\hline \multirow[t]{7}{*}{ XS-A } & XS-A-01 & Loess & 46 & Quartz & $63-150$ & 2.1 & $2.69 \pm 0.10$ & $9.59 \pm 0.25$ & $1.64 \pm 0.12$ & $2.97 \pm 0.15$ & $21.4 \pm 1.2$ & $7.2 \pm 0.6$ & Qiang et al., 2010 \\
\hline & XS-A-02 & Loess & 100 & Quartz & $63-150$ & 3.5 & $2.05 \pm 0.10$ & $7.58 \pm 0.25$ & $1.75 \pm 0.11$ & $2.76 \pm 0.16$ & $29.3 \pm 4.9$ & $10.6 \pm 1.8$ & Qiang et al., 2010 \\
\hline & XS-A-03 & $\begin{array}{l}\text { Aeolian } \\
\text { sand }\end{array}$ & 170 & Quartz & $63-150$ & 1.3 & $1.56 \pm 0.10$ & $7.02 \pm 0.25$ & $1.97 \pm 0.11$ & $2.90 \pm 0.15$ & $35.4 \pm 2.8$ & $12.2 \pm 1.2$ & Qiang et al., 2010 \\
\hline & XS-A-04 & $\begin{array}{l}\text { Aeolian } \\
\text { sand }\end{array}$ & 480 & Quartz & $63-150$ & 1.6 & $1.51 \pm 0.10$ & $7.50 \pm 0.25$ & $1.73 \pm 0.14$ & $2.64 \pm 0.15$ & $67.1 \pm 4.4$ & $25.4 \pm 2.2$ & This study \\
\hline & XS-A-05 & Loess & 510 & Quartz & $63-150$ & 5.8 & $2.87 \pm 0.10$ & $13.5 \pm 0.28$ & $1.80 \pm 0.12$ & $3.31 \pm 0.16$ & $140.8 \pm 6.2$ & $42.5 \pm 2.8$ & Qiang et al., 2010 \\
\hline & XS-A-06 & Loess & 1080 & Quartz & $63-150$ & 5.3 & $2.45 \pm 0.11$ & $11.3 \pm 0.26$ & $1.86 \pm 0.12$ & $3.13 \pm 0.15$ & $172 \pm 6.9$ & $55.0 \pm 3.5$ & Qiang et al., 2010 \\
\hline & XS-A-07 & Loess & 1250 & K-Feldspar & $90-125$ & 2.7 & $2.82 \pm 0.04$ & $10.4 \pm 0.03$ & $1.86 \pm 0.03$ & $4.37 \pm 0.30$ & $290 \pm 10$ & $66.0 \pm 5.0$ & This study \\
\hline \multirow[t]{8}{*}{ XS-B } & XS-B-01 & $\begin{array}{l}\text { Aeolian } \\
\text { sand }\end{array}$ & 350 & K-Feldspar & $90-125$ & 1.3 & $2.22 \pm 0.04$ & $8.32 \pm 0.03$ & $1.69 \pm 0.03$ & $4.10 \pm 0.30$ & $59.0 \pm 1.00$ & $14.0 \pm 1.0$ & This study \\
\hline & XS-B-02 & Loess & 530 & K-Feldspar & $90-125$ & 0.8 & $2.72 \pm 0.04$ & $10.5 \pm 0.03$ & $1.87 \pm 0.03$ & $4.57 \pm 0.30$ & $808 \pm 71$ & $177 \pm 19^{a}$ & This study \\
\hline & XS-B-03 & Loess & 900 & K-Feldspar & $60-125$ & 1.9 & $2.45 \pm 0.10$ & $9.09 \pm 0.26$ & $1.85 \pm 0.06$ & $3.67 \pm 0.10$ & $796 \pm 68$ & $217 \pm 19^{a}$ & This study \\
\hline & XS-B-04 & $\begin{array}{l}\text { Aeolian } \\
\text { sand }\end{array}$ & 950 & K-Feldspar & $90-125$ & 0.7 & $2.17 \pm 0.04$ & $8.72 \pm 0.03$ & $1.70 \pm 0.03$ & $4.19 \pm 0.30$ & $844 \pm 72$ & $201 \pm 22^{a}$ & This study \\
\hline & XS-B-05 & $\begin{array}{l}\text { Aeolian } \\
\text { sand }\end{array}$ & 1635 & K-Feldspar & $90-125$ & 0.9 & $1.75 \pm 0.05$ & $7.41 \pm 0.03$ & $1.96 \pm 0.03$ & $4.19 \pm 0.30$ & $1004 \pm 89$ & $240 \pm 27^{a}$ & This study \\
\hline & XS-B-06 & $\begin{array}{l}\text { Aeolian } \\
\text { sand }\end{array}$ & 1750 & K-Feldspar & $60-125$ & 2.1 & $2.07 \pm 0.08$ & $7.10 \pm 0.24$ & $1.78 \pm 0.06$ & $3.42 \pm 0.09$ & $789 \pm 105$ & $230 \pm 20^{a}$ & This study \\
\hline & XS-B-07 & Loess & 1795 & K-Feldspar & $60-125$ & 4.8 & $2.76 \pm 0.10$ & $10.3 \pm 0.28$ & $1.80 \pm 0.05$ & $3.71 \pm 0.09$ & $693 \pm 69$ & $187 \pm 19^{a}$ & This study \\
\hline & XS-B-08 & Loess & 1990 & K-Feldspar & $90-125$ & 1.9 & $3.12 \pm 0.04$ & $10.7 \pm 0.03$ & $1.89 \pm 0.03$ & $4.64 \pm 0.30$ & $826 \pm 82$ & $178 \pm 21^{a}$ & This study \\
\hline \multirow[t]{6}{*}{ KJ } & KJ-01 & Fluvial sand & 150 & K-Feldspar & $90-125$ & 5.3 & $2.33 \pm 0.09$ & $8.10 \pm 0.24$ & $1.76 \pm 0.05$ & $3.31 \pm 0.10$ & $57.6 \pm 2.8$ & $17.4 \pm 1.0$ & This study \\
\hline & KJ-02 & $\begin{array}{l}\text { Loess/ } \\
\text { Paleosol }\end{array}$ & 260 & K-Feldspar & $90-125$ & 4.2 & $1.50 \pm 0.07$ & $7.42 \pm 0.24$ & $1.58 \pm 0.05$ & $2.94 \pm 0.10$ & $56.8 \pm 1.2$ & $19.3 \pm 0.8$ & This study \\
\hline & $\mathrm{KJ}-03$ & $\begin{array}{l}\text { Aeolian } \\
\text { sand }\end{array}$ & 680 & K-Feldspar & 60-125 & 1.4 & $1.57 \pm 0.07$ & $9.38 \pm 0.27$ & $1.33 \pm 0.05$ & $3.31 \pm 0.09$ & $785 \pm 40$ & $237 \pm 14^{a}$ & This study \\
\hline & KJ-04 & $\begin{array}{l}\text { Aeolian } \\
\text { sand }\end{array}$ & 880 & K-Feldspar & $60-125$ & 2.3 & $1.51 \pm 0.07$ & $7.20 \pm 0.23$ & $1.39 \pm 0.05$ & $2.92 \pm 0.08$ & $802 \pm 452$ & $274 \pm 17^{a}$ & This study \\
\hline & KJ-05 & Loess & 920 & K-Feldspar & $60-125$ & 5.1 & $2.08 \pm 0.09$ & $8.40 \pm 0.25$ & $1.62 \pm 0.05$ & $3.27 \pm 0.09$ & $883 \pm 67$ & $270 \pm 21^{a}$ & This study \\
\hline & KJ-06 & Loess & 1880 & K-Feldspar & $90-125$ & 4.8 & $2.29 \pm 0.04$ & $11.4 \pm 0.03$ & $1.92 \pm 0.03$ & $4.52 \pm 0.30$ & $901 \pm 72$ & $199 \pm 21^{a}$ & This study \\
\hline
\end{tabular}

aEstimated as minimum ages.

${ }^{b}$ Errors: 50 percent of the measured value. 


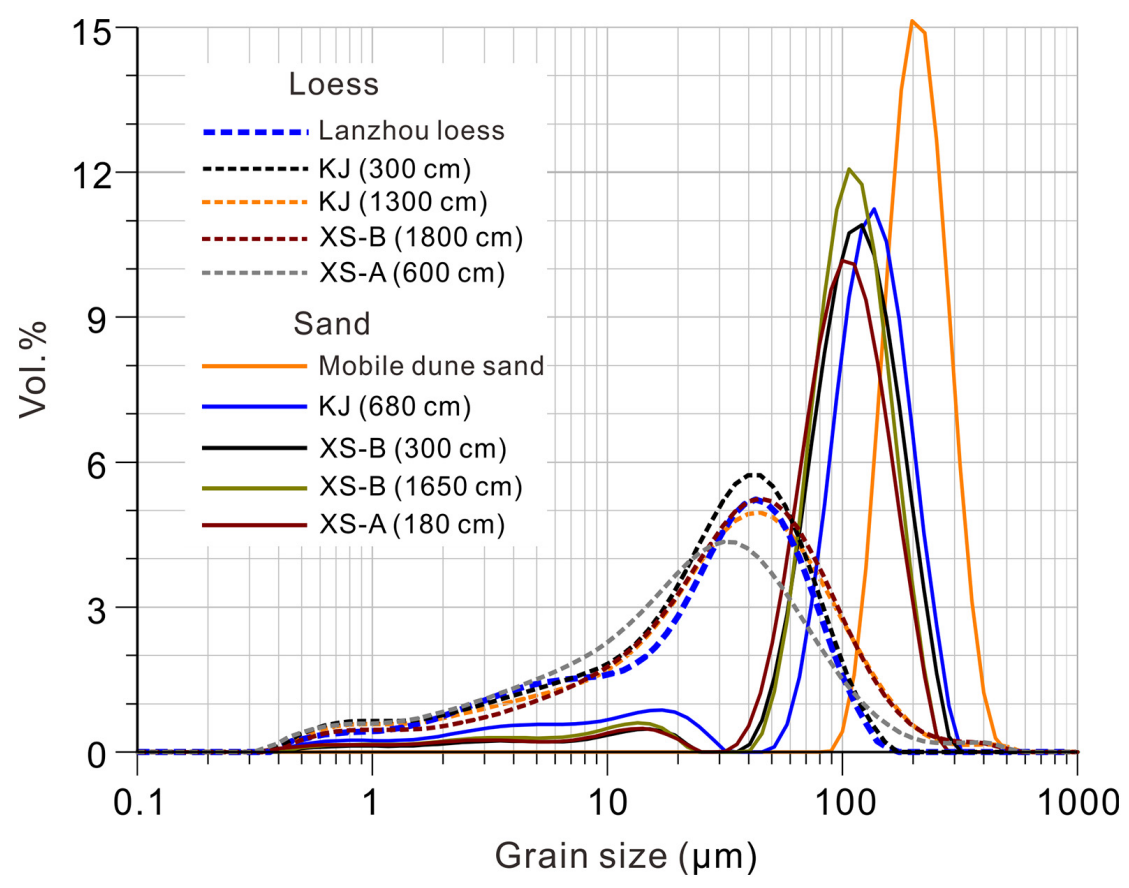

FIGURE 6 | Contrasting grain-size distributions of representative samples of loess and aeolian sand, compared with those of a sample of typical loess from Lanzhou and a sample of mobile dune. Samples depths are given in parentheses.

uncovered at the transition from loess to aeolian sand here strongly suggest that considerable amounts of pre-existing loess may have been significantly and episodically eroded by wind in these areas. As such, combined with evidence from desert marginal sections to the north of the CLP (Stevens et al., 2018), our chronostratigraphic evidence from sites northwest of the CLP lends further support to a proposed "aeolian cannibalism" model of the evolution of the CLP (Kapp et al., 2015; Licht et al., 2016). Evidence from these CLP marginal areas points to previously more extensive loess cover that was subject to considerable erosion beyond the limits of the current CLP. Moreover, at section KJ, the upper loess/weak paleosol was truncated by fluvial process, and riverine deposits occurred between 19.3 and $17.4 \mathrm{ka}$. It is worthwhile noting also that besides eolain erosion, fluvial processes may have been another active agent for reworking of older loess (Licht et al., 2016). However, we note here that it is currently difficult to assess the volume of pre-existing loess in these CLP external sites that may have been removed, and therefore the degree to which these areas may once have made up an extended CLP, as envisaged by Kapp et al. (2015) and Licht et al. (2016). Nonetheless, our results show the important role that reworked loess on the margins of the CLP has in terms of dust sources to the CLP and beyond, as explored below.

\section{The Effect of Wind Erosion of Pre-existing Loess on Dust Influx to the CLP}

Dust from previously deposited loess upwind of the CLP can be entrained and then settled as components of CLP loess accumulation. However, examination of such a dynamic linkage requires a refined chronology of loess sequences. Recently, according to nine well-dated loess sections, Xu et al. (2018) suggested that there is an obvious seesaw pattern in dust accumulations during the past $20 \mathrm{ka}$ across the CLP, and that the higher accumulation rates in the northwestern CLP during 20-15 ka may have been contributed to by loess reworking in upwind regions.

As for specific sites on the CLP, based on high stratigraphic resolution OSL dating, Stevens et al. (2016) measured changes in grain size and mass accumulation rate (MAR) during the last glacial at Xifeng (Figure 1 for location). This study showed that an increase in MAR between 39 and $32 \mathrm{ka}$ at the section was not accompanied by an increase in grain size (Figure 4B), which is in conflict with the prevailing view that the two variables are highly correlated in loess (e.g., Vandenberghe et al., 1997). However, this contradiction and the enhanced dust MAR at Xifeng can potentially be explained by the occurrence of an erosional unconformity from 42.5 to $25.4 \mathrm{ka}$ in section XS-A (Figure 4A): the increased MAR recorded at Xifeng could be a response to the deflation of pre-existing loess in upwind regions, followed by re-deposition downwind on the CLP, while the grain size was relatively invariant because the eroded and subsequently redeposited material itself consisted of loess. Indeed, our observation may explain general mismatches between grain size and dust MAR on sub-orbital timescales seen at a number of sites on the CLP (Stevens and Lu, 2009; Újvári et al., 2016). Similar unconformities in the lower parts of sections XS$\mathrm{B}$ and KJ imply that wind erosion of previously deposited 
loess might occur within a number of intervals prior to the Late Pleistocene.

We suggest that the conversion of upwind loess deposits to dust sources must therefore be considered when using the loess deposits of the CLP to reflect large-scale patterns of Asian dust transport and deposition. For example, dust MAR estimated from loess deposits, some of which have been used to help simulate past relative dust loading (e.g., Albani et al., 2015), may be enhanced at the central CLP sites by this process, potentially leading to overestimates of dust source activity in regions further upwind of the Loess Plateau. Furthermore, the input of homogeneous, silt-sized particles of pre-existing loess from upwind areas would bias the grain size of corresponding loess deposits on the CLP to be less variable or even to be overall smaller compared to their adjacent strata, as grain size is a function not only of wind speed but also source sediment characteristics and distance to source (Újvári et al., 2016). In this case, it is unrealistic to simply explain reductions in grain size as indicating stable or weaker wind regimes, or even strengthened summer monsoonal circulation over the CLP. Rather, intensive aeolian activity may have been occurring in upwind areas at those times.

\section{The Role of Proximal Desert Evolution on Dust Dynamics}

Given that sand-sized particles are transported for short ranges even under strong wind conditions (Pye, 1987), the homogenous, well-sorted sand deposits at the study sites primarily reflect expansions of proximal deserts, e.g., the Tengger Desert and the Mugetan Sandy Land (Figure 1). As shown in section XSA, the recent expansion of the Tengger Desert occurred during 25.4-12.2 ka, or somewhat earlier, which might be supported by the presence of sand deposition in section XS-B, dated as old as $14.0 \mathrm{ka}$ (Figure 4A). Multiple episodes of expansions of proximal deserts are also indicated by the sand deposition in sections $\mathrm{KJ}$ and XS-B.

The grain-size variability along the profiles can further clarify the spatial variation of proximal deserts, since the advance-retreat cycles of the deserts play an important role in defining the grain size of loess deposition (Ding et al., 1999). Beneath the sandy loess/paleosol in the upper parts of the sections, the alternating loess and sand units exhibit contrasting $M_{z}$ values, with relatively uniform values within their respective units (Figure 4A). In addition, in sections XS-B and KJ, the typical loess deposited above sand layers has grain-size distributions very similar to the older loess underlying the sand layers (Figures 4A, 6). These observations imply that when the typical loess is deposited at the sites, the active, previously expanded proximal deserts, represented by the layers of well-sorted sand deposition, may have greatly contracted and/or even been completely fixed following the initiation of loess accumulation. According to investigations on grain sizes of coeval loess deposits along a transection from north to south across the CLP, Ding et al. (1999) proposed that sand content ( $>63 \mu \mathrm{m}$ proportion) of loess in the marginal areas of the CLP could monitor changes in the extent of proximal deserts over the past. Taking section XS$\mathrm{A}$ as an example (Figure 4A), during 66.0-42.5 ka the lower sand content $(<30 \%)$ of the loess suggests a possible distance of $\sim 100 \mathrm{~km}$ to the desert at that time, in light of the model proposed by Ding et al. (1999). This is much larger than the modern distance of $\sim 20 \mathrm{~km}$ (Figure 1B). Similar situations are recorded by sections $\mathrm{KJ}$ and $\mathrm{XS}-\mathrm{B}$, suggesting a dynamic desert environment generally. In this respect, our results are in contrast to the conclusion that the Tengger Desert has been a relatively constant active sandy desert environment since $0.68 \mathrm{Ma}$ (Li et al., 2014). In fact, a paleo-megalake in the desert occurred from 42 to $18{ }^{14} \mathrm{C}$ ka B.P. (Zhang et al., 2002), despite the radiocarbon dates possibly being underestimated (e.g., Madsen et al., 2014). Core sediments from the Badain Jaran Desert also show that from 0.65 to $0.45 \mathrm{Ma}$ a large lake occupied the desert center (Wang et al., 2015). Furthermore, episodic expansions of the $\mathrm{Mu}$ Us Sandy Land during the Marine Isotope Stages (MIS) 2-4 and 6 are illustrated by either erosional hiatuses or sand deposition recorded in the well-dated Jingbian section (Stevens et al., 2018). Moreover, even if we assume that the duration of the paleo-megalake in the Tengger Desert is correct, then the lake expansion seems to coincide with the erosional hiatus from 42 to $25.4 \mathrm{ka}$ in section XS-A, rather than loess deposition. This would suggest that any causal links between these events are quite complicated. Although the available evidence cannot depict the detailed history of proximal deserts, it is plausible that the region may have experienced drastic hydroclimatic changes, which dramatically affect dust emission and transport, and hence the nature of aeolian deposits downwind, as observed at the study sites.

Given the intermediate $M_{z}$ of sandy loess/paleosol, compared to lower loess and sand in section XS-A (Figure 4A), the Tengger Desert may not have retreated as drastically after the recent phase of expansion at 25.4-12.2 ka as occurred previously, when the typical loess units were deposited. Although the weakly developed paleosols perhaps depict a relatively warm and wet climate during some intervals of the Holocene (Figure 4A), the desert may still have had areas of activated aeolian sand sufficient for the sandy loess to be deposited throughout the Late Glacial and the Holocene. In section KJ, the sandy loess/paleosol occurred since $17.4 \mathrm{ka}$, and the $M_{z}$ values are intermediate and less variable until the present. These suggest that the Mugetan Sandy Land could already have existed at this time and may even have been very close to its modern position, likely reflecting proximal desert expansion during the Last Glacial Maximum (LGM) in this area. In fact, the proximal deserts in northern China had expanded greatly during the LGM, and the Tengger Desert and the Gonghe Sandy Land areas have been estimated to be greater by $\sim 30$ and $20 \%$ of their modern sizes, respectively (Lu et al., 2013). In addition, an observed sedimentary hiatus or erosional unconformity in sediments of an alluvial fan-lake system on the southern Alxa Plateau suggests that intense deflation occurred during the LGM (Yu et al., 2019). Intensive wind erosion also occurred in the western Alxa Plateau, as indicated by a prolonged interval of exposure and deflation of high shorelines at the eastern Juyanze paleo-lake (Li et al., 2015). Such large-scale desert expansions and wind erosion in dust source areas were probably driven by an abrupt shift to an extremely cold and dry climate during the LGM (Stevens et al., 2013). 
Given a material linkage between source and sink, it is expected that this large-scale desert expansion would be tracked in loess records downwind. In fact, an increase in the accumulation rate of loess deposits downwind occurred at $\sim 20 \mathrm{ka}$, as evidenced by a $\sim 2.5$-m-thick unit in the Beiguoyuan section on the northern CLP; moreover, the sediment source of this unit shifted abruptly to a local source from the previous well-mixed and recycled remote sources (Stevens et al., 2013). A high MAR of loess deposition during the LGM appears to be observed in large regions, even on the Serbian Titel Loess Plateau (Stevens et al., 2016; Perić et al., 2019). Indeed, based on closely spaced OSL dates, the loess MARs estimated at eight sites on the CLP were distinctly higher from $\sim 23$ to $19 \mathrm{ka}$ (Kang et al., 2015). Under colder and drier climatic conditions during the LGM, enhanced dune activity resulted in erosion of underlying loess strata and hence hiatuses in marginal loess sections (Stevens et al., 2013, 2018). Expanded dune fields and entrained pre-existing loess materials upwind of the CLP would have led to MAR increases together over the CLP. In this regard, the high loess MARs on the CLP during the LGM might not necessarily represent greater wind strength (e.g., Kang et al., 2015) or enhanced silt production through grain to grain impacts and abrasion in migrating dune systems (Amit et al., 2014; Lancaster, 2020), but rather erosion of pre-existing upwind loess and deflation of widespread silt deposits stored in deserts, alluvial fans and river floodplains (e.g., Derbyshire et al., 1998). However, higher wind speeds could still be one of the crucial factors for sand movement in desert environments and sand movement would still be required to erode and mobilize the silt particles locked up in loess deposits upwind of the CLP. Similarly, such a causal linkage between expansions of proximal deserts and loess deposition has to be considered for some intervals prior to the LGM, as suggested by the stratigraphically lower sand layers at the study sites, but assessment on this requires refined chronology of aeolian deposits around the CLP and desert margins.

\section{CONCLUSION}

The alternating strata of loess and well-sorted sand at the study sites show that typical loess deposits have been distributed in upwind areas of the present CLP. The pre-existing loess was eroded by winds capable of moving sands within some intervals of the Quaternary and episodically transformed to an additional dust source for loess accumulation on the CLP. The entrained loess materials will obviously result in changes in grain size and MAR of CLP loess sequences. This process provides a reasonable

\section{REFERENCES}

Aitken, M. J. (1998). An Introduction to Optical Dating: The Dating of Quaternary Sediments by the Use of Photon-stimulated Luminescence. Oxford: Clarendon Press.

Albani, S., Mahowald, N. M., Winckler, G., Anderson, R. F., Bradtmiller, L. I., Delmonte, B., et al. (2015). Twelve thousand years of dust: the Holocene global dust cycle constrained by natural archives. Clim. Past Discuss. 11, 869-903. doi: 10.5194/cp-11-869-2015 explanation for the recently observed contradictions between the two parameters in the late glacial loess deposits on the central CLP. Furthermore, the variable extent of proximal deserts also plays an important role in dust emission and transport, giving rise to major changes in dust accumulation rates on the CLP, especially during the LGM expansion of proximal deserts. Our results firstly provide stratigraphic evidence supporting at least some cannibalization of previously deposited loess (Kapp et al., 2015) outside of the modern CLP, and highlight dynamic dust activity in upwind regions that apparently complicate climatic interpretations from Chinese loess sequences. Despite of some dating uncertainties presented here, the significantly contrasting stratigraphic variability strongly suggests that the history of dust activity in upwind regions is of particular significance for thorough understanding of climate and dust changes recorded by Quaternary loess deposits. Thus, more well-dated aeolian sequences from broad upwind areas of the CLP, in combination with other types of environmental records, would be important to elucidate these dust processes, including changes in desert environment and their potential forcing mechanisms.

\section{DATA AVAILABILITY STATEMENT}

The raw data supporting the conclusions of this article will be made available by the authors, without undue reservation.

\section{AUTHOR CONTRIBUTIONS}

MQ designed the work. MQ, TS, and GL wrote the text. TS, GL, and JC participated in dating analyses. $\mathrm{LH}, \mathrm{XW}$, and $\mathrm{WL}$ participated in the field and laboratory works. All authors read and approved the submission.

\section{FUNDING}

This research was supported by the National Natural Science Foundation of China (grants 42071109, 41671190) and the National Key R\&D Program of China (grant 2017YFA0603402).

\section{ACKNOWLEDGMENTS}

We thank Hui Zhao and Shengli Yang for their assistance in luminescence dating and data analyses and Fengshan Li and Ganggang Wang for their assistance in the field.

Amit, R., Enzel, Y., Mushkin, A., Gillespie, A., Batbaatar, J., Crouvi, O., et al. (2014). Linking coarse silt production in Asian sand desert and Quaternary accretion of the Chinese Loess Plateau. Geology 42, 23-26. doi: 10.1130/G34857.1

Biscaye, P. E., Grousset, F. E., Revel, M., Van der Gaast, S., Zielinski, A., Vaars, A., et al. (1997). Asian provenance of glacial dust (stage 2) in the GISP2 ice core, Summit, Greenland. J. Geophys. Res. 102, 26765-26781. doi: 10.1029/ 97JC01249

Buylaert, J. P., Jain, M., Murray, A. S., Thomsen, K. J., Thiel, C., and Sohbati, R. (2012). A robust feldspar luminescence dating method for middle and 
late Pleistocene sediments. Boreas 41, 435-451. doi: 10.1111/j.1502-3885.2012. 00248.x

Buylaert, J. P., Yeo, E. Y., Thiel, C., Yi, S. W., Stevens, T., Thompson, W., et al. (2015). A detailed post-IR IRSL chronology for the last interglacial soil at the Jingbian loess site (northern China). Quat. Geochronol. 30, 194-199. doi: 10.1016/j.quageo.2015.02.022

Derbyshire, E., Meng, X. M., and Kemp, R. A. (1998). Provenance, transport and characteristics of modern aeolian dust in western Gansu Province, China, and interpretation of the Quaternary loess record. J. Arid Environ. 39, 497-516. doi: 10.1006/jare.1997.0369

Ding, Z. L., Sun, J. M., Rutter, N. W., Rokosh, D., and Liu, T. S. (1999). Changes in sand content of loess deposits along a north-south transect of the Chinese Loess Plateau and implications for desert variations for desert variations. Quat. Res. 52, 56-62. doi: 10.1006/qres.1999.2045

Guérin, G., Mercier, N., and Adamiec, G. (2011). Dose-rate conversion factors: update. Ancient TL 29, 5-8.

Guo, Z. T., Ruddiman, W. F., Hao, Q. Z., Wu, H. B., Qiao, Y. S., Zhu, R. X., et al. (2002). Onset of Asian desertification by $22 \mathrm{Myr}$ ago inferred from loess deposits in China. Nature 416, 159-163. doi: 10.1038/41 $6159 a$

Hovan, S. A., Rea, D. K., Pisias, N. G., and Shackleton, N. J. (1989). A direct link between the China loess and marine $\delta^{18} \mathrm{O}$ records: Aeolian flux to the north Pacific. Nature 340, 296-298. doi: 10.1038/340296a0

Huntley, D. J., and Baril, M. R. (1997). The K content of the K-feldspars being measured in optical dating or in thermoluminescence dating. Ancient TL 15, $11-13$.

Huntley, D. J., and Hancock, R. G. V. (2001). The Rb contents of the K-feldspars being mea-sured in optical dating. Ancient TL 19, 43-46.

Kang, S. G., Roberts, H. M., Wang, X. L., An, Z. S., and Wang, M. (2015). Mass accumulation rate changes in Chinese loess during MIS2, and asynchrony with records from Greenland ice cores and North Pacific Ocean sediments during the Last Glacial Maximum. Aeolian Res. 19, 251-258. doi: 10.1016/j.aeolia.2015. 05.005

Kapp, P., Pullen, A., Pelletier, J. D., Russell, J., Goodman, P., and Cai, F. L. (2015). From dust to dust: Quaternary wind erosion of the Mu Us Desert and Loess Plateau, China. Geology 43, 835-838. doi: 10.1130/G36724.1

Lancaster, N. (2020). On the formation of desert loess. Quat. Res. 96, 105-122. doi: 10.1017/qua.2020.33

Li, G. Q., Jin, M., Duan, Y. W., Madsen, D. B., Li, F. L., Yang, L. P., et al. (2015). Quartz and Kfeldspar luminescence dating of a Marine Isotope Stage 5 megalake in the Juyanze Basin, central Gobi Desert, China. Palaeogeogr. Palaeoclimatol. Palaeoecol. 440, 96-109. doi: 10.1016/j.palaeo.2015.08.033

Li, Z. J., Sun, D. H., Chen, F. H., Wang, F., Zhang, Y. B., Guo, F., et al. (2014). Chronology and paleoenvironmental records of a drill core in the central Tengger Desert of China. Quat. Sci. Rev. 85, 85-98. doi: 10.1016/j.quascirev. 2013.12.003

Licht, A., Pullen, A., Kapp, P., Abell, J., and Giesler, N. (2016). Eolian cannibalism: Reworked loess and fluvial sediment as the main sources of the Chinese Loess Plateau. Geol. Soc. Am. Bull. 128, 944-956. doi: 10.1130/B31375.1

Licht, A., van Cappelle, M., Abels, H. A., Ladant, J. B., Trabucho-Alexandre, J., France-Lanord, C., et al. (2014). Asian monsoon in a late Eocene greenhouse world. Nature 513, 501-506. doi: 10.1038/nature13704

Liu, T. S., and Ding, Z. L. (1998). Chinese loess and the paleomonsoon. Annu. Rev. Earth Planet. Sci. 26, 111-145. doi: 10.1146/annurev.earth.26. 1.111

Lu, H. Y., Yi, S. W., Xu, Z. W., Zhou, Y. L., Zeng, L., Zhu, F. Y., et al. (2013). Chinese deserts and sand fields in Last Glacial Maximum and Holocene Optimum. Chin. Sci. Bull. 58, 2775-2783. doi: 10.1007/s11434-0135919-7

Madsen, D. B., Lai, Z. P., Sun, Y. J., Rhode, D., Liu, X. J., and Brantingham, P. J. (2014). Late Quaternary Qaidam lake histories and implications for an MIS 3 “Greatest Lakes" period in northwest China. J. Paleolimnol. 51, 161-177. doi: 10.1007/s10933-012-9662-x

Perić, Z., Adolphi, E. L., Stevens, T., Újvári, G., Zeeden, C., Buylaert, J.-P., et al. (2019). Quartz OSL dating of late Quaternary Chinese and Serbian loess: A cross Eurasian comparison of dust mass accumulation rates. Quat. Int. 502, 30-44. doi: 10.1016/j.quaint.2018.01.010
Prescott, J. R., and Hutton, J. T. (1994). Cosmic ray contributions to dose rates for luminescence and ESR dating: large depths and long-term time variations. Rad. Meas. 23, 497-500. doi: 10.1016/1350-4487(94)90086-8

Pye, K. (1987). Aeolian Dust and Dust Deposits. London: Academic Press.

Qiang, M. R., Chen, F. H., Wang, Z. T., Niu, G. M., and Song, L. (2010). Aeolian deposits at the southeastern margin of the Tengger Desert (China): Implications for surface wind strength in the Asian dust source area over the past 20,000 years. Palaeogeogr. Palaeoclimatol. Palaeoecol. 286, 66-80. doi: 10.1016/j.palaeo. 2009.12.005

Qiang, M. R., Liu, Y. Y., Jin, Y. X., Song, L., Huang, X. T., and Chen, F. H. (2014). Holocene record of eolian activity from Genggahai Lake, northeastern Qinghai-Tibetan Plateau, China. Geophys. Res. Lett. 41, 589-595. doi: 10.1002/ 2013GL058806

Rea, D. K. (1994). The paleoclimatic record provided by eolian deposition in the deep sea: The geologic history of wind. Rev. Geophys. 32, 159-195. doi: 10.1029/93RG03257

Shao, Y. P., Wyrwoll, K. H., Chappell, A., Huang, J. P., Lin, Z. H., McTainsh, G. H., et al. (2011). Dust cycle: An emerging core theme in Earth system science. Aeolian Res. 2, 181-204. doi: 10.1016/j.aeolia.2011.02.001

Stevens, T., Adamiec, G., Bird, A. F., and Lu, H. Y. (2013). An abrupt shift in dust source on the Chinese Loess Plateau revealed through high sampling resolution OSL dating. Quat. Sci. Rev. 82, 121-132. doi: 10.1016/j.quascirev.2013.10.014

Stevens, T., and Lu, H. Y. (2009). Optically stimulated luminescence dating as a tool for calculating sedimentation rates in Chinese loess: comparisons with grain-size records. Sedimentology 56, 911-934. doi: 10.1111/j.1365-3091.2008. 01004.x

Stevens, T., Armiitage, S. J., Lu, H. Y., and Thomas, D. S. G. (2006). Sedimentation and diagenesis of Chinese loess: Implication for the preservation of continuous, high-resolution climate records. Geology 34, 849-852. doi: 10.1130/G22472.1

Stevens, T., Buylaert, J. P., Lu, H. Y., Thiel, C., Murry, A., Frechen, M., et al. (2016). Mass accumulation rate and monsoon records from Xifeng, Chinese Loess Plateau, based on a luminescence age model. J. Quat. Sci. 31, 391-405. doi: $10.1002 /$ jqs. 2848

Stevens, T., Buylaert, J. P., Thiel, C., Újvári, G., Yi, S. W., Murray, A. S., et al. (2018). Ice-volume-forced erosion of the Chinese Loess Plateau global Quaternary stratotype site. Nat. Commun. 9, 983-994. doi: 10.1038/s41467-018-03329-2

Sun, J. M., and Ding, Z. L. (1998). Deposits and soils of the past 130,000 years at the desert-loess transition in northern China. Quat. Res. 50, 148-156. doi: 10.1006/qres.1998.1989

Sun, J. M., Zhang, M. Y., and Liu, T. S. (2001). Spatial and temporal characteristics of dust storms in China and its surrounding regions, 1960-1999: Relation to source area and climate. J. Geophys. Res. 106, 10325-10333. doi: 10.1029/ 2000JD900665

Sun, Y. B., Clemens, S. C., Morrill, C., Lin, X. P., Wang, X. L., and An, Z. S. (2012). Influence of Atlantic meridional overturning circulation on the East Asian winter monsoon. Nat. Geosci. 5, 46-49. doi: 10.1038/ngeo1326

Újvári, G., Kok, J. F., Varga, G., and Kovács, J. (2016). The physics of windblown loess: Implications for grain size proxy interpretations in Quaternary paleoclimate studies. Earth Sci. Rev. 154, 247-278. doi: 10.1016/j.earscirev.2016. 01.006

Uno, I., Eguchi, K., Yumimoto, K., Takermura, T., Shimizu, A., Uematsu, M., et al. (2009). Asian dust transported one full circuit around the globe. Nat. Geosci. 2, 557-560. doi: 10.1038/ngeo583

Vandenberghe, J., An, Z. S., Nugteren, G., Lu, H. Y., and Van Huissteden, K. (1997). New absolute time scale for the Quaternary climate in the Chinese Loess region by grain-size analysis. Geology 25, 35-38. doi: 10.1130/009176131997025<0035:NATSFT<2.3.CO;2

Wang, F., Sun, D. H., Chen, F. H., Bloemendal, J., Guo, F., Li, Z. J., et al. (2015). Formation and evolution of the Badain Jaran Desert, North China, as revealed by a drill core from the desert centre by geological survey. Palaeogeogr. Palaeoclimatol. Palaeoecol. 426, 139-158. doi: 10.1016/j.palaeo.2015.03.011

Xu, Z. W., Stevens, T., Yi, S. W., Mason, J. A., and Lu, H. Y. (2018). Seesaw pattern in dust accumulation on the Chinese Loess Plateau forced by late glacial shifts in the East Asian monsoon. Geology 46, 871-874. doi: 10.1130/G45105.1

Yi, S. W., Buylaert, J.-P., Murray, A. S., Lu, H. Y., Thiel, C., and Zeng, L. (2016). A detailed post-IR IRSL dating study of the Niuyangzigou loess site in northeastern China. Boreas 45, 644-657. doi: 10.1111/bor.12185 
Yi, S. W., Li, X. S., Han, Z. Y., Lu, H. Y., Liu, J. F., and Wu, J. (2018). High resolution luminescence chronology for Xiashu Loess deposits of Southeastern China. J. Asian Earth Sci. 155, 188-197. doi: 10.1016/j.jseaes.2017.11.027

Yu, S.-Y., Du, J. H., Hou, Z. F., Shen, J., and Colman, S. M. (2019). Late-Quaternary dynamics and palaeoclimatic implications of an alluvial fan-lake system on the southern Alxa Plateau, NW China. Geomorphology 327, 1-13. doi: 10.1016/j. geomorph.2018.10.012

Zhang, H. C., Wünnemann, B., Ma, Y. Z., Peng, J. L., Pachur, H. J., Li, J. J., et al. (2002). Lake level and climate changes between 42,000 and $18,000{ }^{14} \mathrm{C}$ yr B.P. in the Tengger Desert, northwestern China. Quat. Res. 58, 62-72. doi: 10.1006/qres.2002.2357
Conflict of Interest: The authors declare that the research was conducted in the absence of any commercial or financial relationships that could be construed as a potential conflict of interest.

Copyright (๑) 2021 Qiang, Stevens, $L i, H u$, Wang, Lang and Chen. This is an openaccess article distributed under the terms of the Creative Commons Attribution License (CC BY). The use, distribution or reproduction in other forums is permitted, provided the original author(s) and the copyright owner(s) are credited and that the original publication in this journal is cited, in accordance with accepted academic practice. No use, distribution or reproduction is permitted which does not comply with these terms. 